\title{
WILEY-VCH
}

DOI: 10.1002/ ((please add manuscript number))

Article type: (Communication)

\section{Covalent Organic Framework based Microspheres as Anode Material for Rechargeable}

\section{Sodium Batteries}

Bidhan C Patra, Sabuj Kanti Das, ${ }^{\dagger}$ Arnab Ghosh, ${ }^{\dagger}$ Anish Raj K, ${ }^{\dagger}$ Parikshit Moitra, Matthew Addicoat, Sagar Mitra, Asim Bhaumik, * Santanu Bhattacharya* and Anirban Pradhan*

B. C. Patra, S. K. Das, Dr. P. Moitra, Prof. A. Bhaumik,* Prof. S. Bhattacharya* and Dr. A. Pradhan*, Indian Association for the Cultivation of Science, Jadavpur, Kolkata 700032, INDIA.

Email-msab@iacs.res.in (Prof. A. Bhaumik), director@iacs.res.in (Prof. S. Bhattacharya) and msap5@iacs.res.in (Dr. A. Pradhan).

P. Moitra, Technical Research Centre, Indian Association for the Cultivation of Science, Jadavpur, Kolkata 700032, INDIA.

A. Ghosh, A. R. K, Prof. S. Mitra, Indian Institute of Technology, Bombay, Powai, Mumbai, Maharashtra 400076, INDIA.

Dr. M. Addicoat, School of Science and Technology, Nottingham Trent University, Clifton Lane, Nottingham, NG11 8NS, UK.

Keywords: Covalent organic framework, anode material, sodium batteries, cyclic voltammetry, cycling performance.

\section{ABSTRACT}

Covalent organic frameworks (COFs) promise several benefits as martials in terms of gas adsorption, optoelectronic devices etc. However, energy storage ability of COFs has not been well studied, especially in sodium batteries. In this report, for the first time, a covalent organic 


\section{WILEY-VCH}

framework (COF), $\mathrm{C} 3 \mathrm{Cy} \mathrm{COF}$ is used as an anode with high capacity in sodium batteries. The C3Cy COF exhibits an initial reversible capacity of $246 \mathrm{~mA} \mathrm{~h} \mathrm{~g}^{-1}$ and a reversible capacity of $125 \mathrm{~mA} \mathrm{~h} \mathrm{~g}^{-1}$ is recorded after 500 cycles, at the current rate of $30 \mathrm{~mA} \mathrm{~g}^{-1}$. The $\mathrm{C} 3 \mathrm{Cy} \mathrm{COF}$ further exhibits superior $\mathrm{Na}^{+}$ion storage capability at different current rates. The $\mathrm{Na}^{+}$ions storage viability of $\mathrm{C} 3 \mathrm{Cy} \mathrm{COF}$ arises mainly because of its open ordered nanoporous framework, which provides reversible accommodation for ions. This work opens up a promising new approach for further utilization of COFs as an electrode materials in rechargeable sodium batteries.

\section{INTRODUCTION}

Depletion of natural resources is a serious problem, which drive a significant scientific research activity aimed at securing the planet's ongoing energy supply. ${ }^{[1-2]}$ This issue may be achieved by storing energy using a suitable energy storage device with high durability and low cost. ${ }^{[3]}$ Rechargeable batteries would be more viable candidate for electrochemical energy storage. ${ }^{[4-5]}$ Due to their light weight, portability, and high energy density, lithium-ion batteries are among the most promising ones among the energy storage devices. However, due to limited natural abundance $\left(0.02 \mathrm{~g} \mathrm{~kg}^{-1}\right.$ in earth crust), the continuous supply of lithium metal as an indispensable element in lithium-ion batteries might not be viable in future. The use of sodium instead of lithium, in rechargeable batteries could be a way to circumvent lithium's resource problem, as is pronounced by its high affluence i.e., $27.1 \mathrm{~g} \mathrm{Kg}^{-1}$ of earth crust and $11 \mathrm{~g} \mathrm{~L}^{-1}$ in seawater. From both sustainability and economical points of view, sodium is the better option to replace lithium in rechargeable batteries. However, the current by available sodium-ion batteries are based on the inorganic insertion metal oxides. ${ }^{[6-11]}$ The large scale production of these inorganic metal oxides using ceramic process imposes a serious impact on the environment. Therefore, there is an increasing demand for the green and sustainable electrode materials for sodium-ion batteries. ${ }^{[12]}$ As an alternative to conventional inorganic materials, redox-active organic compounds offer the opportunity to develop low 


\section{WILEY-VCH}

cost and environmentally sustainable i.e., "green batteries" owing to their sustainability, structural variety, flexibility and minimal environmental footprint. ${ }^{[13-15]}$

The design of organic electrode materials is not a new concept, since the first organic cathode based on dichloro isocyanuric acid was proposed in $1969 .{ }^{[16]}$ After that, several organic active materials such as organo sulfur compounds, conjugated carbonyl compounds, polyimides, quinones, carboxylates, imidazole based polymer etc. $^{[17-22]}$ have been used as active electrode materials for the energy storage. However, a new organic material with higher specific capacity, conductivity and long term accessibility for the sodium batteries still continues to be a challenge.

Covalent organic frameworks (COFs) are a class of crystalline polymeric materials, prepared by the integration of organic building block to form two or three dimensional ordered structurs. ${ }^{[23]}$ This structural order and competent $\pi$-stacking with the size of the electrolyte ion makes it a promising substrate for the ideal charge transport throughout the channel. ${ }^{[24-25]}$ COFs are currently most often exploited for other applications like gas storage and separation, ${ }^{[26-27]}$ drug delivery, ${ }^{[28]}$ catalysis, ${ }^{[29]}$ pseudocapacitor, ${ }^{[30-31]}$ proton conduction ${ }^{[32-33]}$ and many optoelectronic devices. ${ }^{[34]}$ Direct application of COF materials for the sodium ion batteries is however, still nascent research avenue. Fundamental need for an organic anode material is the reversible electrochemical redox reaction occurs via a conjugated structure. This conjugation helps in intramolecular electron transfer making the material highly redox active. Organic anode materials based on normal Schiff-base condensation reaction forming $\mathrm{C}=\mathrm{N}$ double bond play a pivotal role for the electrochemical activity. ${ }^{[35]}$ Presence of an azomethine group in the structural unit conjugated with whole polymer is expected to induces the polymer to be a better electrode.

Herein we present a new $\mathrm{COF}$ material constructed by $\mathrm{C}_{3}-\mathrm{C}_{3}$ symmetrical topology designated as $\mathrm{C} 3 \mathrm{Cy}$, is used as an anode material for the first time in sodium batteries (Figure 1). The $\mathrm{C} 3 \mathrm{Cy} \mathrm{COF}$ anode shows a high initial reversible capacity of $246 \mathrm{~mA} \mathrm{~h} \mathrm{~g}^{-1}$ and a 


\section{WILEY-VCH}

capacity of $125 \mathrm{~mA} \mathrm{~h} \mathrm{~g}^{-1}$ observed after 500 cycles in sodium battery. The sustainability of $\mathrm{C} 3 \mathrm{Cy} \mathrm{COF}$ anode in sodium batteries may inspire further applications of COFs in sodium batteries.

\section{Experimental section}

\section{1. Materials}

All reagents were supplied from best available commercial sources and were used without further purification. 1, 3, 5-Tris (4-formylphenyl)-benzene (C3) and 2, 4, 6-Tris(4aminophenyl)-1, 3, 5-triazine (Cy) were synthesized by previously reported procedure ${ }^{[36-37]}$. Tetrakis (triphenylphosphine) palladium (0), was received from sigma Aldrich. 4-fromyl phenyl boronic acid, Dimethyl acetamide, o-dichlorobenzene etc. were purchased from Spectrochem, India. Other solvents, acid, bases were supplied from the local commercial source.

\section{2. Instrumentation}

FT-IR spectra of the synthesized samples were recorded using a Nicolet MAGNA-FT IR 750 Spectrometer Series II. Solid state ${ }^{13} \mathrm{C}$ CP MAS NMR spectrum of C3Cy COF was recorded in a $500 \mathrm{MHz}$ BrukerAvance III spectrometer at a MAS frequency of $10 \mathrm{kHz}$. X-Ray diffraction patterns of the powder samples were obtained with a Bruker AXS D-8 Advanced SWAX diffractometer using $\mathrm{Cu}-\mathrm{K} \alpha(0.15406 \mathrm{~nm})$ radiation. $\mathrm{N}_{2}$ adsorption/desorption isotherms of the sample was recorded using an Autosorb 1C (Quantachrome, USA) at $77 \mathrm{~K}$. The sample was first degassed at $120^{\circ} \mathrm{C}$ for overnight and set for measurement. Pore size distribution (PSD) was calculated by using NLDFT considering the carbon/slit-cylindrical pore model. Scanning electron microscopic analysis was performed with a JEOL JEM 6700F field-emission scanning electron microscope (FESEM). High resolution Transmission electron microscopic (HR-TEM) images of the synthesized polymer were obtained using a JEOL JEM 2010 transmission electron microscope operated at $200 \mathrm{kV}$. The sample was dispersed in isopropanol and drop coated on a copper grid TEM window. X-ray photoelectron 


\section{WILEY-VCH}

spectroscopy (XPS) was performed on an Omicron nanotech operated at $15 \mathrm{kV}$ and $20 \mathrm{~mA}$. TGA instruments thermal analyzer TA-SDT Q-600 was used for thermogravimetric analysis (TGA) by heating the samples from room temperature to $800^{\circ} \mathrm{C}$ with heating rate of 10 ${ }^{\circ} \mathrm{C} /$ min under $\mathrm{N}_{2}$ atmosphere. The ${ }^{1} \mathrm{H}$ and ${ }^{13} \mathrm{C}$ NMR spectra were obtained using a Bruker AVANCE III-400 MHz spectrometer. ${ }^{1} \mathrm{H}$ NMR spectra were collected at $400 \mathrm{MHz}$ with chemical shift referenced to the residual peak in $\mathrm{CDCl}_{3}(\delta: \mathrm{H} 7.26 \mathrm{ppm}$. Multiplicities are written as s (singlet), $\mathrm{d}$ (doublet), $\mathrm{t}$ (triplet), $\mathrm{m}$ (multiplet) and br (broad).

\section{3. Electrochemical Measurements}

To evaluate the electrochemical performances of the $\mathrm{C} 3 \mathrm{CyCOF}$, a slurry was prepared by mixing the same as an active material, super $\mathrm{P}$ carbon as a conductive additive, sodium alginate and styrene butadiene rubber (SBR) as binder with an overall ratio of 65:25:8:2 (by wt.) respectively in water. The slurry was blade cast onto carbon-coated copper foil and then dried at $50{ }^{\circ} \mathrm{C}$ for $48 \mathrm{~h}$. The electrodes were cut into disks with a diameter of $10 \mathrm{~mm}$ with an average active material loading of $1.65 \mathrm{mg} \mathrm{cm}^{-2}$. Coin-type (CR2016) cells were assembled in an argon-filled glovebox. To investigate the electrochemical performances of C3Cy COF with respect to sodium, metallic sodium was used as counter/reference electrode. Celgard 2400 was incorporated as separator between the two electrodes. $1 \mathrm{M} \mathrm{NaPF}_{6}$ in 1:1 (v/v) mixture of ethylene carbonate (EC) and dimethyl carbonate (DMC) was incorporated as electrolyte (40 $\mu \mathrm{L})$. A cyclic voltammetry (CV) study was carried out at a scan rate of $0.02 \mathrm{mV} \mathrm{s}^{-1}$ within the potential window 0.001-3.0 V vs $\mathrm{Na}^{+} / \mathrm{Na}$ using Biologic VMP-3. The Galvanostatic chargedischarge experiments were performed using an Arbin BT-2000 within the potential window of $0.05-1.6 \mathrm{~V} v s \mathrm{Na}^{+} / \mathrm{Na}$. The capacities were evaluated based on the active mass of the $\mathrm{C} 3 \mathrm{Cy}$ COF in the electrode. All of the electrochemical measurements were carried out at a constant temperature of $20^{\circ} \mathrm{C}$.

\section{4. Synthesis of 1, 3, 5-tris (4-formylphenyl)-benzene (C3)}




\section{WILEY-VCH}

1, 3, 5-Tribromobenzene (500 mg, $1.59 \mathrm{mmol})$, (4-formylphenyl) boronic acid (953 mg, 6.35 mmol) and $\mathrm{Na}_{2} \mathrm{CO}_{3}(1.68 \mathrm{~g}, 15.9 \mathrm{mmol})$ were dissolved in toluene $(30 \mathrm{~mL})$, water $(5 \mathrm{~mL})$ and ethanol $(10 \mathrm{~mL})$. The solution was degassed three times, $\mathrm{Pd}\left(\mathrm{PPh}_{3}\right)_{4}(183.7 \mathrm{mg}, 0.159 \mathrm{mmol})$ was added under an Ar stream and the mixture was degassed three times again. The resulting solution was then heated at $90{ }^{\circ} \mathrm{C}$ for $48 \mathrm{~h}$. The organic layer was then decanted and the aqueous layer was extracted two times using $\mathrm{CH}_{2} \mathrm{Cl}_{2}$. The combined organic layer was washed with water and evaporated. The crude product was purified by chromatography on silica gel using n-hexane/ EtOAc (10\%) as the eluent to give the title compound $\mathrm{C} 3$ as an offwhite solid (465 mg, 75\%).

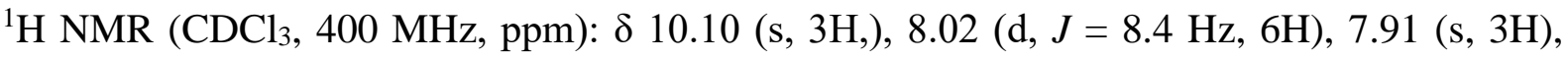
$7.87(\mathrm{~d}, J=8.4 \mathrm{~Hz}, 6 \mathrm{H}) .{ }^{13} \mathrm{C} \mathrm{NMR}\left(\mathrm{CDCl}_{3}, 125 \mathrm{MHz}, \mathrm{ppm}\right): \delta 191.8,146.4,141.7,135.9$, 130.6, 128.1, 126.6. ESI HRMS calcd (M+) 390.13412, found 390.13011.

\section{5. Synthesis of 2, 4, 6-tris(4-aminophenyl)-1, 3, 5-triazine (Cy)}

4-Amino benzonitrile ( $\mathrm{gm}$ ) was taken in a round bottom flask equipped with an ice bath and $1 \mathrm{ml}$ triflic acid was added to this drop-wise. The solution was then stirred overnight at room temperature. $200 \mathrm{ml}$ of distilled water was added to dilute the solution and neutralized with 2 (M) $\mathrm{NaOH}$ solution. A deep yellow precipitate was washed with water several times and dried under vacuum. (Yellow solid, $1.9 \mathrm{~g}, 95 \%$ ).

${ }^{1} \mathrm{H}$ NMR (DMSO- $\left.d_{6}, 400 \mathrm{MHz}, \mathrm{ppm}\right): \delta 8.36(\mathrm{~d}, J=8.8 \mathrm{~Hz}, 6 \mathrm{H}), 6.70(\mathrm{~d}, J=8.4 \mathrm{~Hz}, 6 \mathrm{H})$, $5.91(\mathrm{~s}, 6 \mathrm{H}) .{ }^{13} \mathrm{C} \mathrm{NMR}\left(\mathrm{CDCl}_{3}, 125 \mathrm{MHz}, \mathrm{ppm}\right): \delta 169.5,152.9,130.6,130.1,122.9,113.1$. ESI HRMS calcd (M+) 354.16341, found 354.15741.

\section{6. Synthesis of $\mathrm{CBCy} \mathrm{COF}$}

$3 \mathrm{ml}$ of a 1:1 mixture of $o$-Dichlorobenzene $(o$-DCB) $: n$-butanol $(1: 1)$ mixture was added to the mixture of 1, 3, 5-Tris(4-formylphenyl)-benzene (C3) $(0.3 \mathrm{mmol}, 117.1 \mathrm{mg})$ and 2,4,6Tris(4-aminophenyl)-1,3,5-triazine (Cy) (0.3mmol, $106.2 \mathrm{mg})$ using an acetic-acid catalyst (6 $\mathrm{M}, 0.2 \mathrm{ml})$ in a schlenk tube $(50 \mathrm{ml})$ and sonicated for $1 \mathrm{~h}$. Then the tube was degassed via 


\section{WILEY-VCH}

freeze-pump-thaw cycles for three times and flame sealed under vacuum. The tube was then heated statically at $120{ }^{\circ} \mathrm{C}$ for 3 days. The yellowish precipitate was collected via centrifugation, washed several times with dimethylacetamide (DMAC), tetrahydrofuran (THF) and dry acetone to remove the trapped guest molecules. The powder was collected and dried at $120{ }^{\circ} \mathrm{C}$ under vacuum overnight to produce $\mathrm{C} 3 \mathrm{Cy} \mathrm{COF}$ in an isolated yield of $90 \%$.

\section{Results and discussion}

The powder X-ray diffraction study of $\mathrm{C} 3 \mathrm{Cy}$ COF showed the presence of five prominent peaks with the most intense peak at two theta value of $4.02^{\circ}$ indicating the presence of (110) plane of the regularly ordered hexagonal lattice. Other peaks at $6.8^{\circ}, 8.07^{\circ}, 10.7^{\circ}$ and $25.8^{\circ}$ indicate the existence of (210), (200), (130) and (002) planes, respectively (Figure 2b). The crystal structure was simulated by Density-Functional Tight-Binding (DFTB) including the effects of Lennard-Jones dispersion ${ }^{[38]}$ considering the $\mathrm{AA}, \mathrm{AB}$, and slipped layer stacking. This C3Cy COF adopts the $\mathrm{P}_{1}$ space group with $\mathrm{a}=26.0009, \mathrm{~b}=25.887, \mathrm{c}=7.12809, \alpha=$ 79.6841, $\beta=93.5581$ and $\gamma=59.679$. The simulated slipped-AA structure showed almost perfect agreement with the experimental PXRD patterns (Figure 2a). The $\pi-\pi$ stacking distance between the two layers is $\sim 3.489 \AA$ (Figure 2d). The alignment of the $\pi$ - $\pi$ stacking planes in experimental PXRD (Figure 2b) is due to the (002) facet, which was again validated parallel alignment of $2 \mathrm{D}$ sheets in the HR-TEM images, shown in figure 3 . The selected-area (Figure 3b) FFT pattern was analyzed in figure 3 (d-f) which reflects the (002) facet of the C3Cy COF with a $d$-spacing of $\sim 3.4 \AA$. The observed (002) facet was further simulated, which is shown in figure $3 \mathrm{~g}, 3 \mathrm{~h}$ and $3 \mathrm{i}$ with the corresponding $3 \mathrm{~d}, 3 \mathrm{e}$ and $3 \mathrm{f} F \mathrm{FT}$ pattern respectively. HR-TEM results suggest that $\mathrm{C} 3 \mathrm{Cy} \mathrm{COF}$ has periodicities in all three dimensions. ${ }^{[39]}$ Reverse-AB stacking mode did not replicate the experimental XRD pattern which lies in the space group of P1 with $a=26.0566, b=26.0558, c=6.12928, \alpha=\beta=90$ and $\gamma=60.081$. Stacking energies were also calculated to establish the energetically more favorable structure (ESI, Table S1). The slipped-AA (Figure S5a) stacking has a total crystal 


\section{WILEY-VCH}

stacking energy of $-71.75 \mathrm{kcal} / \mathrm{mol}$ which is relatively higher than that of AA $(-62.34$ $\mathrm{kcal} / \mathrm{mol})$ and $\mathrm{AB}(-34.97 \mathrm{kcal} / \mathrm{mol})$ stacking modes. Pawley refinement (Material studio 7.0) was carried out to indicate the exact peak assignment of the theoretical PXRD with the experimental pattern, and it shows a good agreement with the $R_{p}$ and $R_{w p}$ values of $4.91 \%$ and $6.54 \%$, respectively.

FT-IR spectra shown in Figure 4a confirms the formation of imine $(-\mathrm{C}=\mathrm{N})$ bond at $1690 \mathrm{~cm}^{-1}$ and other two peaks at $1595 \mathrm{~cm}^{-1}$ and $1503 \mathrm{~cm}^{-1}$ indicating the presence of phenyl triazine core $-\mathrm{C}=\mathrm{N}$ stretching bond and symmetrical aromatic $\mathrm{C}=\mathrm{C}$ bond, respectively. ${ }^{[40]}$ From the solid state ${ }^{13} \mathrm{C}$ CP-MAS spectra, the peak at $158.1 \mathrm{ppm}$ indicates the formation of imine bond and a strong peak at $\sim 170$ ppm confirms the presence of triazine carbon atom (Figure $4 \mathbf{c}){ }^{[41]}$ X-ray photoelectron spectroscopy (XPS) also reveals the presence of carbon, nitrogen and oxygen atom in the $\mathrm{C} 3 \mathrm{Cy}$ COF moiety. Fitted $\mathrm{C}_{1 \mathrm{~s}}$ spectra shows $\mathrm{C}=\mathrm{C}, \mathrm{C}=\mathrm{N}$ at $283.7 \mathrm{eV}$ and $287 \mathrm{eV}$ respectively (Figure 4d). Deconvoluted $\mathrm{N}_{1 \mathrm{~s}}$ spectra at $397.5 \mathrm{eV}$ clearly indicates the presence of $\mathrm{C}=\mathrm{N}$ bonded nitrogen atoms. Another peak near $399 \mathrm{eV}$ indicates the presence of triazine ring present in the $\mathrm{C} 3 \mathrm{Cy} \mathrm{COF}$ (Figure 4e). Volumetric $\mathrm{N}_{2}$ adsorption/desorption isotherm of the $\mathrm{C} 3 \mathrm{Cy} \mathrm{COF}$ was measured at $77 \mathrm{~K}$, which shows a typical type-I isotherm a characteristic of mesoporous materials (Figure 4f). Brunauer-Emmett-Teller (BET) model was applied between the pressure range $\left(\mathrm{P} / \mathrm{P}_{0}\right)$ of 0.05 and 0.136 to determine the experimental surface area to be $120 \mathrm{~m}^{2} \mathrm{~g}^{-1}$. This low surface area is due to the non-specific displacement of the $\mathrm{C} 3 \mathrm{Cy} \mathrm{COF}$ layers throughout the framework. ${ }^{[42]}$ The pore size was calculated by NL-DFT, yielding a diameter of $2.3 \mathrm{~nm}$ with a pore volume of $0.0631 \mathrm{cc} \mathrm{g}^{-1}$ supporting the mesoporosity of the present COF material (inset Figure $4 \mathbf{f}$ ). The absence of hysteresis indicates the existence of ordered hexagonal mesopores with pore width of 2.3nm. ${ }^{[23]}$ Scanning electron microscopy (SEM) images of the C3Cy COF also reveals the spherical morphology (Figure S8a). Thermal stability of C3Cy COF was investigated by thermogravimetric analysis (TGA) which manifest the complete removal of solvent molecule 


\section{WILEY-VCH}

from the pore of the $\mathrm{C} 3 \mathrm{Cy} \mathrm{COF}$ material at $130{ }^{\circ} \mathrm{C}$. Slower decrease in the mass loss up to $\sim 500{ }^{\circ} \mathrm{C}$ shows the high temperature durability of the C3Cy COF (Figure S8b). Beyond this temperature, the gradual weight loss was observed presumably because of the rupture of the COF backbone.

Recently, the application of the Schiff-base COF as electro-active material is encouraging towards the rechargeable batteries. ${ }^{[43-45]}$ To interrogate the viability of covalent organic frameworks as an electrode material, in this study, $\mathrm{C} 3 \mathrm{Cy} \mathrm{COF}$ was employed as a working electrode material with respect to sodium. The $\mathrm{Na}^{+}$ion storage performances of $\mathrm{C} 3 \mathrm{Cy} \mathrm{COF}$ in sodium batteries are shown in Figure 5. The inset of Figure 5a shows the first scan of cyclic voltammetry study of $\mathrm{C} 3 \mathrm{Cy}$ in the voltage range of $0.001-3.0 \mathrm{~V}$ against $\mathrm{Na}^{+} / \mathrm{Na}$ redox system at $0.02 \mathrm{mV} \mathrm{s}^{-1}$ scan rate. During the first cathodic scan, an intense sharp peak at around $1.0 \mathrm{~V}$ and a broad peak at the potential range of $0.5-0.9 \mathrm{~V}$ were observed. The reduction peak at 1.0 $\mathrm{V}$ could be attributed to $\mathrm{Na}^{+}$insertion into $\mathrm{C} 3 \mathrm{Cy} \mathrm{COF}$. The broad peak observed ranging from $0.9 \mathrm{~V}$ to $0.5 \mathrm{~V}$ arises due to the irreversible formation of solid electrolyte interphase (SEI) on the surface of $\mathrm{C} 3 \mathrm{Cy} \mathrm{COF}$ anode accompanied by further $\mathrm{Na}^{+}$ion insertion into $\mathrm{C} 3 \mathrm{Cy} \mathrm{COF}$. However, after the first cycle, the nearly unchanged pair of cathodic peaks and anodic peaks with similar intensities correspond to the highly reversible two-steps insertion-extraction of $\mathrm{Na}^{+}$ion into $\mathrm{C} 3 \mathrm{Cy} \mathrm{COF}$ (Figure 5a). The galvanostatic charge-discharge profiles of $\mathrm{C} 3 \mathrm{Cy}$ $\mathrm{COF}$ anode at a current rate of $30 \mathrm{~mA} \mathrm{~g}^{-1}$, within the potential range $0.05-1.6 \mathrm{~V} v \mathrm{Na}^{+} / \mathrm{Na}$ are shown in Figure 5b. Figure 5c represents the corresponding charge-discharge cycling performance of $\mathrm{C} 3 \mathrm{Cy} \mathrm{COF}$ at $30 \mathrm{~mA} \mathrm{~g}^{-1}$ current rate. Due to irreversible consumption of $\mathrm{Na}^{+}$ ions during the formation of SEI in the initial discharge, a highly specific discharge capacity (770 $\mathrm{mA} \mathrm{h} \mathrm{g}^{-1}$ ) with relatively low coulombic efficiency ( 44\%) was observed during the first cycle. However, C3Cy COF delivered an initial reversible specific capacity of $246 \mathrm{~mA} \mathrm{~h} \mathrm{~g}^{-1}$ at the second cycle and a high capacity of $125 \mathrm{~mA} \mathrm{~h} \mathrm{~g}^{-1}$ was observed after 500 cycles with the average capacity decay rate of $0.1 \%$ per cycle. From the fundamental viewpoint, maximum 


\section{WILEY-VCH}

theoretical capacity, which corresponds to one sodium ion insertion per $-\mathrm{C}=\mathrm{N}$ moiety, could be achieved at $233 \mathrm{~mA} \mathrm{~h} \mathrm{~g}^{-1}$. Theoretical capacity of the C3Cy COF electrode was calculated by the following formula: ${ }^{[46,47]}$

$$
\mathrm{C}_{t}=\frac{\mathrm{F} \times 1000}{\mathrm{M} \times 3600}
$$

where, $\mathrm{C}_{t}=$ theoretical capacity, $\mathrm{F}=$ Faraday constant and $\mathrm{M}=$ molecular weight per active site

It has been reported that super $\mathrm{P}$ carbon could exhibit as much as $100 \mathrm{~mA} \mathrm{~h} \mathrm{~g}^{-1}$ as anode material in sodium batteries. ${ }^{[48]}$ Therefore, it is possible at most $38 \mathrm{~mA} \mathrm{~h} \mathrm{~g}^{-1}\left[=100 \mathrm{~mA} \mathrm{~h} \mathrm{~g}{ }^{-1} \times\right.$ (25 wt\% super P / $65 \mathrm{wt} \%$ active material)] capacity contribution comes from super P carbon additive. To interrogate the excellent capability of $\mathrm{Na}^{+}$ion storage by the $\mathrm{C} 3 \mathrm{Cy} \mathrm{COF}$, the sodium batteries were cycled at different current rates. Figure $5 \mathbf{d}$ represents $\mathrm{Na}^{+}$ion storage performance of $\mathrm{C} 3 \mathrm{Cy} \mathrm{COF}$ in sodium battery at the current densities of 30, 50, 100 and 200 $\mathrm{mA} \mathrm{g}^{-1}$, respectively. The average capacities $245,200,170$ and $145 \mathrm{~mA} \mathrm{~h} \mathrm{~g}^{-1}$ were recorded at 30, 50, 100 and $200 \mathrm{~mA} \mathrm{~g}^{-1}$ current densities, indicating excellent $\mathrm{Na}^{+}$ion storage capability of $\mathrm{C} 3 \mathrm{Cy} \mathrm{COF}$ in sodium batteries. In $\mathrm{C} 3 \mathrm{Cy} \mathrm{COF}$, there is delocalized $\pi$-electron cloud which resides througout the periphery of one ring. During the discharge process, $\mathrm{Na}^{+}$ion inserts into C3Cy $\mathrm{COF}$, where the inserted $\mathrm{Na}^{+}$ion could be stabilized through "cation- $\pi$ interaction" "[49] with delocalized $\pi$-electron cloud as shown in Figure 6.

In order to check the viability of $\mathrm{C} 3 \mathrm{Cy} \mathrm{COF}$ as an anode material in lithium batteries, the electrochemical characterizations of $\mathrm{C} 3 \mathrm{Cy} \mathrm{COF}$ were also performed with respect to lithium metal (ESI Section S4). C3Cy COF exhibited an initial reversible capacity of $478 \mathrm{~mA} \mathrm{~h} \mathrm{~g}^{-1}$ at $2^{\text {nd }}$ cycle and a high specific capacity of $392 \mathrm{~mA} \mathrm{~h} \mathrm{~g}^{-1}$ was retained after 50 cycles (rate of capacity decay $=0.36 \%$ per cycle), indicating an extremely stable cyclability. The electochemical performances of $\mathrm{C} 3 \mathrm{Cy} \mathrm{COF}$ with respect to the lithium are given in Figure S10. 


\section{WILEY-VCH}

\section{Conclusion}

In conclusion, a new triazine based covalent organic framework, $\mathrm{C} 3 \mathrm{Cy} \mathrm{COF}$ has been designed, successfully synthesized and characterized. The C3Cy COF was employed as an anode material in both lithium and sodium ion batteries. A high specific capacity with excellent capacity retention was observed for $\mathrm{C} 3 \mathrm{Cy}$ COF anode in both the alkali metal batteries. It is believed that the current application of $\mathrm{C} 3 \mathrm{Cy} \mathrm{COF}$ as green and sustainable electrode material in sodium batteries could open up avenues for commercial application of covalent organic frameworks in rechargeable batteries. To the best of our knowledge this is the first report of a COF material which could be used as sodium ion storage with excellent durability. This finding should be of considerable interest to the material chemistry community for such attractive and unprecedented property.

\section{Supporting Information}

Supporting Information is available from the Wiley Online Library or from the author .

DOI: *** Synthetic procedures, PXRD, gas adsorption, FT-IR, ${ }^{13} \mathrm{C}$ solid-state NMR, TGA, SEM, TEM, and crystallographic data (PDF).

\section{Author Contributions}

BCP, AP and SB designed the scheme. ${ }^{\dagger} \mathrm{SKD}, \mathrm{AG}$ and ARK contributed equally. ARK and AG designed and conducted the electrochemical experiments. SM suggested the electrochemical experiments. MA undertook the calculations.

\section{Notes}

The authors declare no competing financial interest. 


\section{WILEY-VCH}

\section{Acknowledgements}

AP \& BCP acknowledge DST for funding through INSPIRE program. Prof. SB acknowledges support received from DST (J. C. Bose fellowship) and that from DRU at IACS. The authors AG, ARK and SM acknowledge the financial support by National Center for Photovoltaic Research and Education (NCPRE), IIT Bombay.

\section{References}

[1] A. C. Dillon, Chem. Rev. 2010, 110, 6856.

[2] Z. Yang, J. Zhang, M. C. W. Kintner-Meyer, X. Lu, D. Choi, J. P. Lemmon, J. Liu, Chem. Rev. 2011, 111, 3577.

[3] B. Dunn, H. Kamath, J. M. Tarascon, Science 2011, 334, 928.

[4] X. Cui, J. Chen, T. Wang, W. Chen, Sci. Rep. 2014, 4, 5310.

[5] K. Kang, Y. S. Meng, J. Bréger, C. P. Grey, G. Ceder, Science 2006, 311, 977.

[6] S. Komaba, C. Takei, T. Nakayama, A. Ogata, N. Yabuuchi, Electrochem. Commun. 2010, $12,355-358$.

[7] R. Berthelot, D. Carlier, C. Delmas, Nat. Mater. 2011, 10, 74-80.

[8] D. Kundu, E. Talaie, V. Duffort, L. F. Nazar, Angew. Chem. Int. Ed. 2015, 54, 3431-3448.

[9] N. Yabuuchi, M. Yano, H. Yoshida, S. Kuze, S. Komaba, J. Electrochem. Soc. 2013, 160, A3131-A3137.

[10] N. Yabuuchi, K. Kubota, M. Dahbi, S. Komaba, Chem. Rev., 2014, 114, 11636-11682.

[11] Y. U. Park, D. H. Seo, H. S. Kwon, B. Kim, J. Kim, H. Kim, I. Kim, H. I. Yoo, K. Kang, J. Am. Chem. Soc. 2013, 135, 13870-13878.

[12] D. Larcher, J. M. Tarascon, Nat. Chem. 2015, 7, 19-29. 


\section{WILEY-VCH}

[13] A. L. Goodwin, Nat. Mater.2010, 9, 7-8.

[14] H. Wu, S. A. Shevlin, Q. Meng, W. Guo, Y. Meng, K. Lu, Z. Wei, Z. Guo, Adv. Mater. 2014, 26, 3338-3343.

[15] V. A. Oltean, B. Philippe, S. Renault, R. F. Duarte, H. Rensmo, D. Brandell, Chem. Mater., 2016, 28, 8742-8751.

[16] D. L. Williams, J. J. Byrne, J. S. Driscoll, J. Electrochem. Soc. 1969, 116, 2-4.

[17] Y. Xu, M. Zhou, Y. Lei, Materialstoday 2017, doi.org/10.1016/j.mattod.2017.07.005.

[18] Y. L. Liang, P. Zhang, Z. L. Tao, J. Chen, Chem. Sci. 2013, 4, 1330-1337.

[19] Z. Song, H. Zhan, Y. Zhou, Angew. Chem. Int. Ed. 2010, 49, 8444-8448.

[20] M. Yao, H. Senoh, S. Yamazaki, Z. Siroma, T. Sakai, K. Yasuda, J. Power Sources. 2010, $195,8336-8340$.

[21] Y. Park, D.-S. Shin, S. H. Woo, N. S. Choi, K. H. Shin, S. M. Oh, K. T. Lee, S. Y. Hong, Adv. Mater. 2012, 24, 3562-3567.

[22] B. C. Patra, S. Khilari, L. Satyanarayana, D. Pradhan, A. Bhaumik, Chem. Commun. 2016, 52, 7592-7595.

[23] A. P. Cote, A. I. Benin, N. W. Ockwig, M. O’Keeffe, A. J. Matzger, O. M. Yaghi, Science 2005, 310, 1166-1170.

[24] X. Feng, L. Liu, Y. Honsho, A. Saeki, S. Seki, S. Irle, Y. Dong, A. Nagai, D. L. Jiang, Angew. Chem. Int. Ed. 2012, 51, 2618-2622.

[25] F. Xu, S. B. Jin, H. Zhong, D. Wu, X. Q. Yang, X. Chen, H. Wei, R. Fu, D. Jiang, Sci. Rep. 2015, 5, 8225. 


\section{WILEY-VCH}

[26] N. Huang, X. Chen, R. Krishna, D. Jiang, Angew. Chem. Int. Ed. 2015, 54, 2986-2990.

[27] H. Furukawa, O. M. Yaghi, J. Am. Chem. Soc.2009, 131, 8875-8883.

[28] Q. Fang, J. Wang, S. Gu, R. B. Kaspar, Z. Zhuang, J. Zheng, H. Guo, S. Qiu, Y. Yan, J. Am. Chem. Soc. 2015, 137, 8352-8355.

[29] S. Y. Ding, J. Gao, Q. Wang, Y. Zhang, W. G. Song, C. Y. Su, W. Wang, J. Am. Chem. Soc. 2011, 133, 19816-19822.

[30] C. R. Mulzer, L. Shen, R. P. Bisbey, J. R. McKone, N. Zhang, H. D. Abruña, W. R. Dichtel, ACS Cent. Sci. 2016, 2, 667-673.

[31] C. R. Deblase, K. E. Silberstein, T. Truong, H. D. Abruña, W. R. Dichtel, J. Am. Chem. Soc. 2013, 135, 16821-16824.

[32] H. Xu, S. Tao, D. Jiang, Nat. Mater. 2016, DOI: 10.1038/ nmat4611.

[33] S. Chandra, T. Kundu, S. Kandambeth, R. BabaRao, Y. Marathe, S. M. Kunjir, R. Banerjee, J. Am. Chem. Soc. 2014, 136, 6570-6573.

[34] S. Wan, J. Guo, J. Kim, H. Ihee, D. Jiang, Angew. Chem. Int. Ed. 2009, 48, 5439-5442.

[35] E. Castillo-Martinez, J. Carretero-Gonzalez, M. Armand, Angew. Chem. Int. Ed. 2014, 53, 5341-5345.

[36] Z. M. Gong, B. Yang, H. P. Lin, Y. Y. Tang, Z. Y. Tang, J. J. Zhang, H. M. Zhang, Y. Y. Li, Y. S. Xie, Q. Li, ACS Nano 2016, 10, 4228-4235.

[37] R. Gomes, P. Bhanja, A. Bhaumik, Chem. Commun. 2015, 51, 10050-10053.

[38] Materials Studio Release Notes v.4.4 (Accelrys Software, San Diego, 2008). 


\section{WILEY-VCH}

[39] J. Guo, Y. Xu, S. Jin, L. Chen, T. Kaji, Y. Honsho, M. A. Addicoat, J. Kim, A. Saeki, H.

Ihee, S. Seki, S. Irle, M. Hiramoto, J. Gao, D. Jiang, Nature Communications 2013, 4, 2736.

[40] S. Lin, Y. Hou, X. Deng, H. Wang, S. Suna, X. Zhang, RSC Adv., 2015, 5, 41017-41024.

[41] A. Halder, S. Kandambeth, B. P. Biswal, G. Kaur, N. C. Roy, M. Addicoat, J. K. Salunke, S. Banerjee, K. Vanka, T. Heine S. Verma, R. Banerjee, Angew. Chem. Int. Ed. 2016, 55, 7806-7810.

[42] S. Wang, Q. Wang, P. Shao, Y. Han, X. Gao, L. Ma, S. Yuan, X. Ma, J. Zhou, X. Feng, B. Wang, J. Am. Chem. Soc. 2017, 139, 4258.

[43] H. Yang, S. Zhang, L. Han, Z. Zhang, Z. Xue, J. Gao, Y. Li, C. Huang, Y. Yi, H. Liu, Y. Li, ACS Appl. Mater. Interfaces 2016, 8, 5366.

[44] L. Bai, Q. Gao, Y. Zhao, J. Mater. Chem. A 2016, 4, 14106.

[45] D. H. Yang, Z. Q. Yao, D. Wu, Y.-H. Zhang, Z. Zhou, X.-H. Bu, J. Mater. Chem. A 2016, 4, 18621.

[46] Z. Song, H. Zhou, Energy Environ. Sci. 2013, 6, 2280-2301.

[47] J. Qian, Y. Xiong, Y. Cao, X. Ai, H. Yang, Nano Lett. 2014, 14, 1865-1869.

[48] C. M. Wu, P. I. Pan, Y.-W. Cheng, C.-P. Liu, C.-C. Chang, M. Avdeev, S. K. Lin, J. Power Sources. 2017, 340, 14-21.

[49] S. Gao, G. Shi, H. Fang, Nanoscale 2016, 8, 1451-1455. 


\section{WiLEY-VCH}

Figure 1.
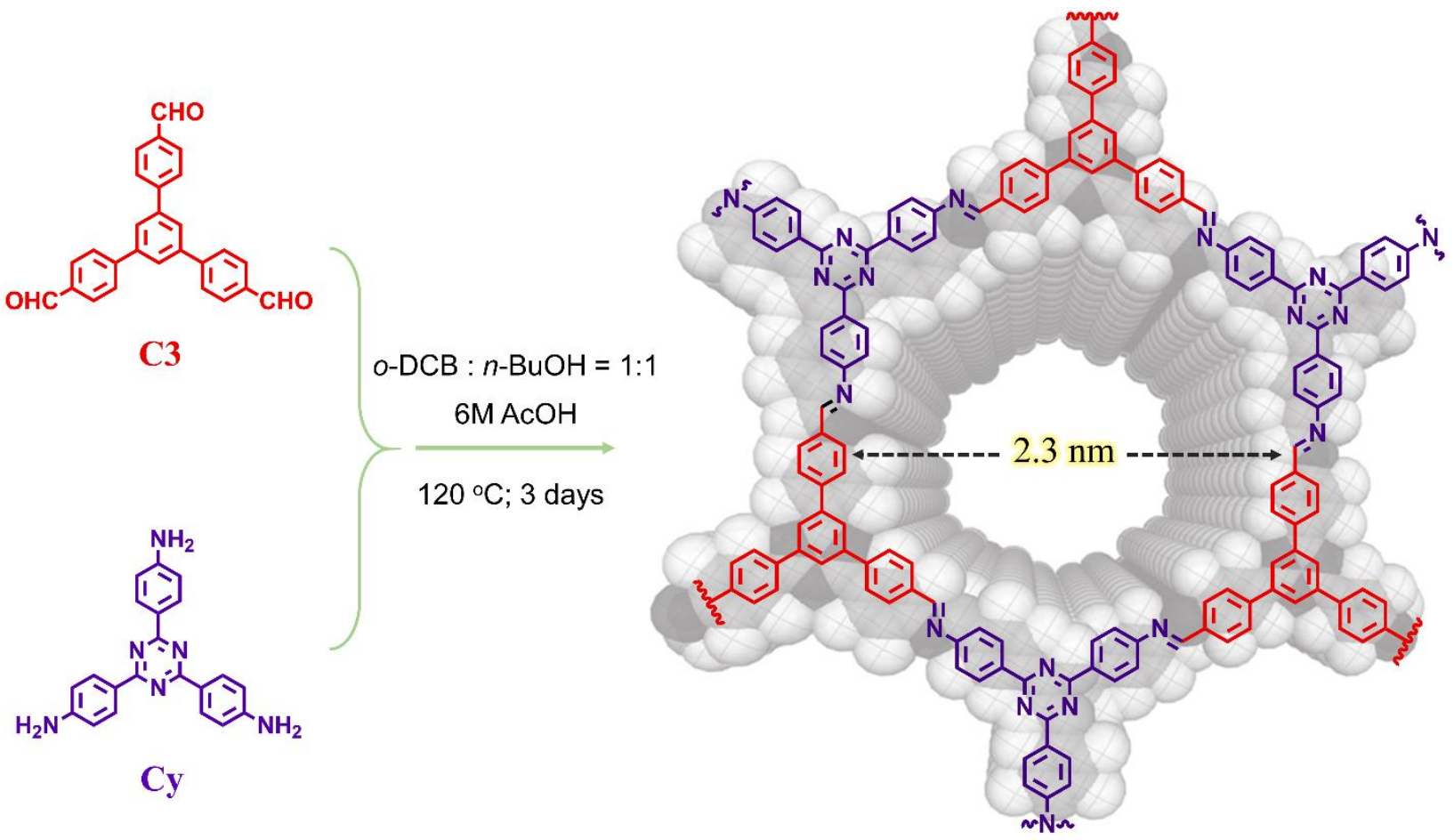

Figure 1: Synthetic scheme for C3Cy COF. 


\section{WILEY-VCH}

Figure 2.
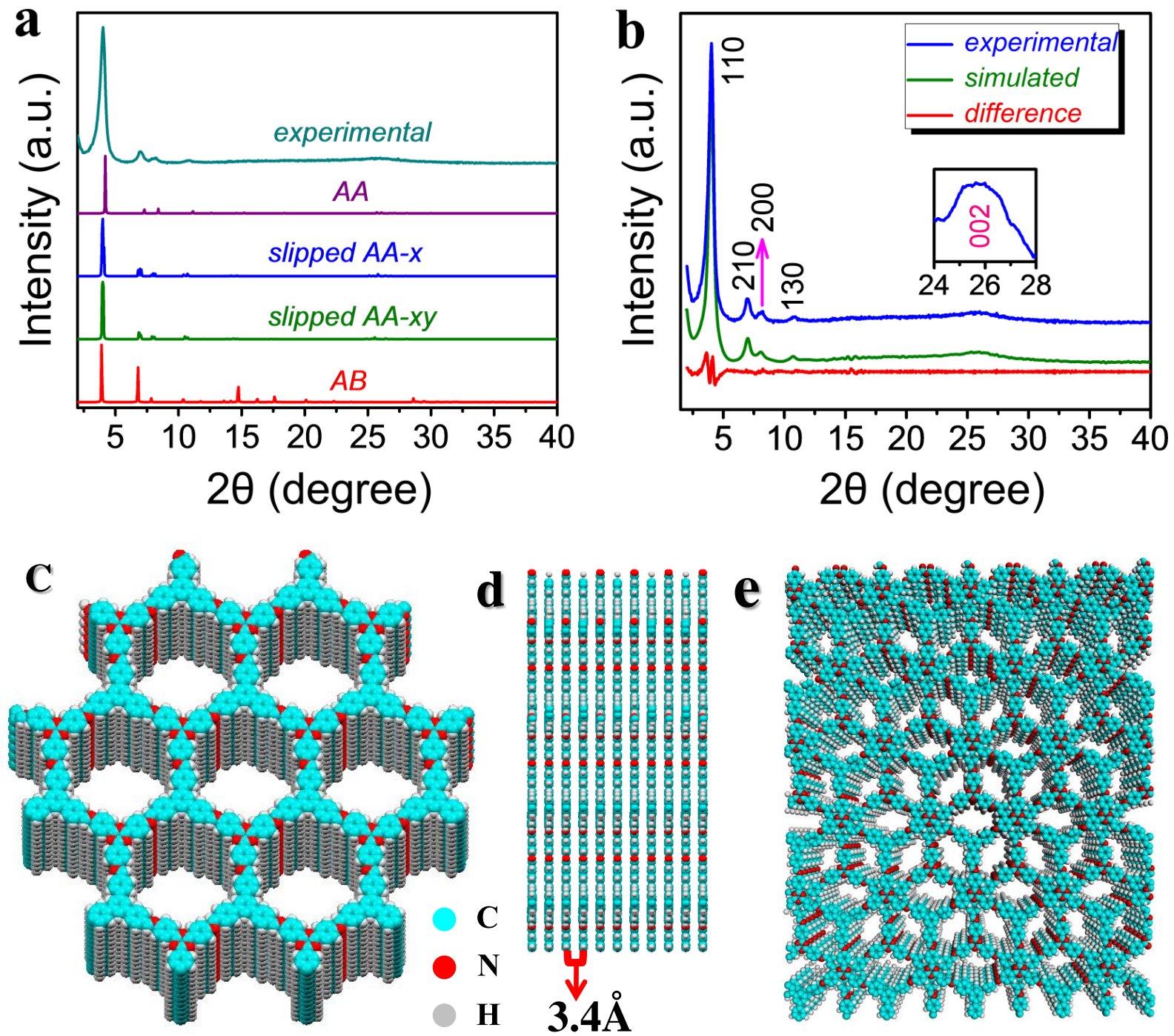

Figure 2: (a) Comparison between the experimental and the theoretical PXRD patterns. (b) Pawley refinement of the experimental PXRD data. (c, e) Possible eclipsed and staggered conformation of the C3Cy COF. (d) Stacking distance between the two adjacent layers. 


\section{WILEY-VCH}

Figure 3.
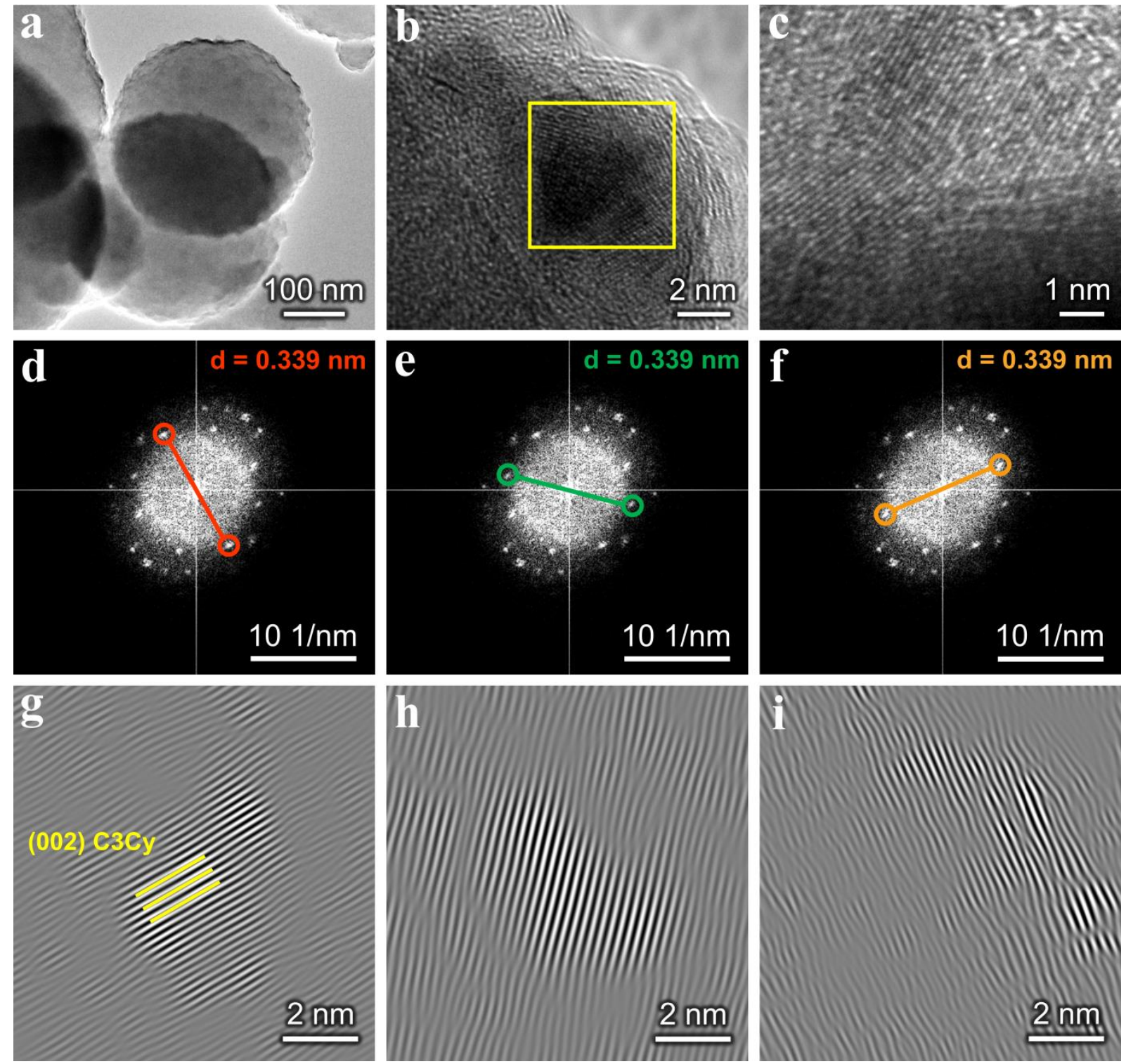

Figure 3: (a) TEM image of C3Cy COF structure. (b, c) HR-TEM images of parallel alignment (002) facet of C3Cy COF (d, e, f) FFT pattern of the (002) plane. (g, h, i) simulated HRTEM images corresponding to $\mathrm{d}$, e and f respectively. 
Figure 4.
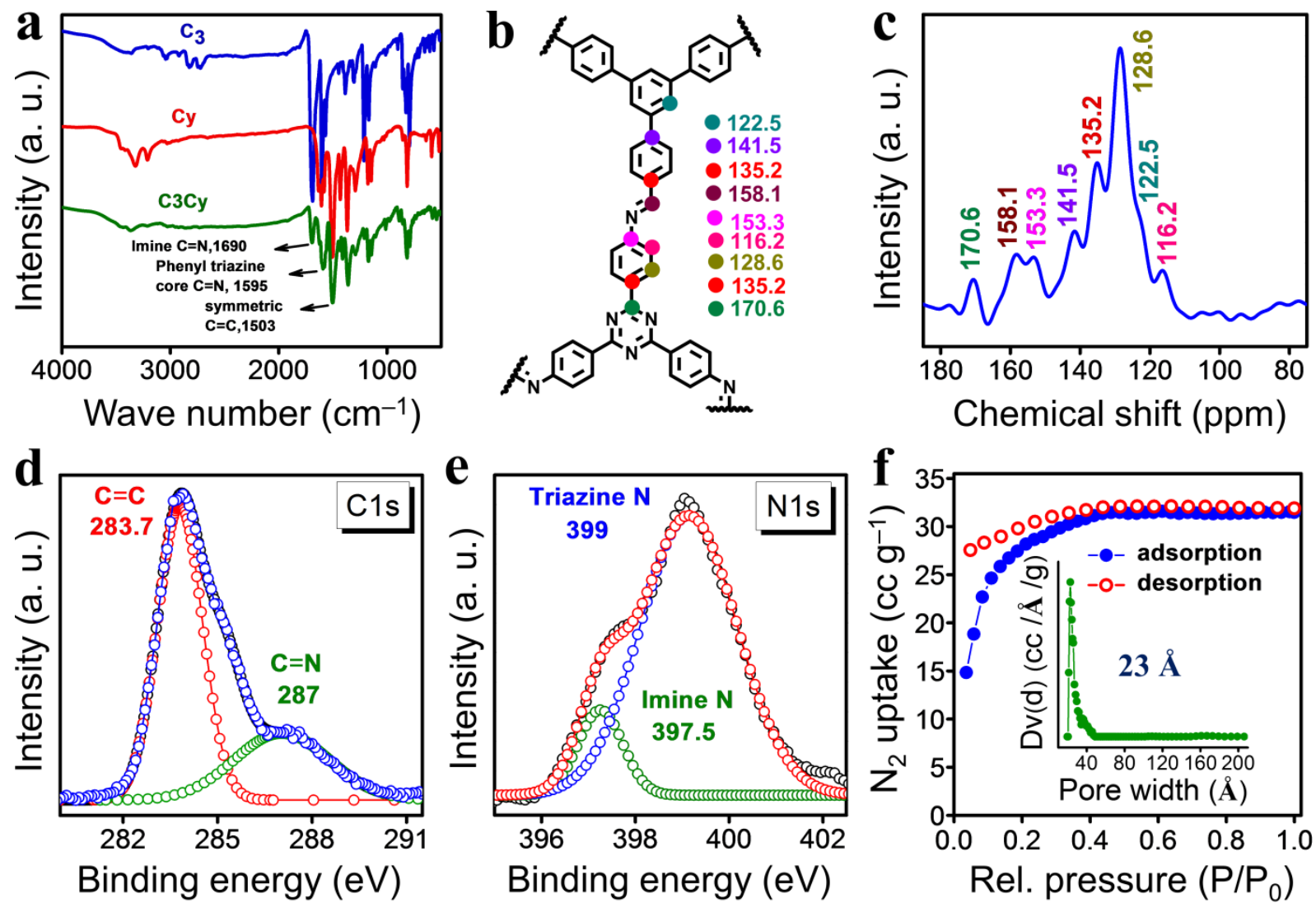

Figure 4: (a) Infrared spectra of C3, Cy and C3Cy COF. (b) Repeating unit of C3Cy COF. (c) Solid state ${ }^{13} \mathrm{C}$ MAS-NMR spectra of C3Cy COF. (d, e) XPS spectrum of C1s and N1s. (f) Volumetric nitrogen adsorption/desorption isotherm of C3Cy COF. 
Figure 5.
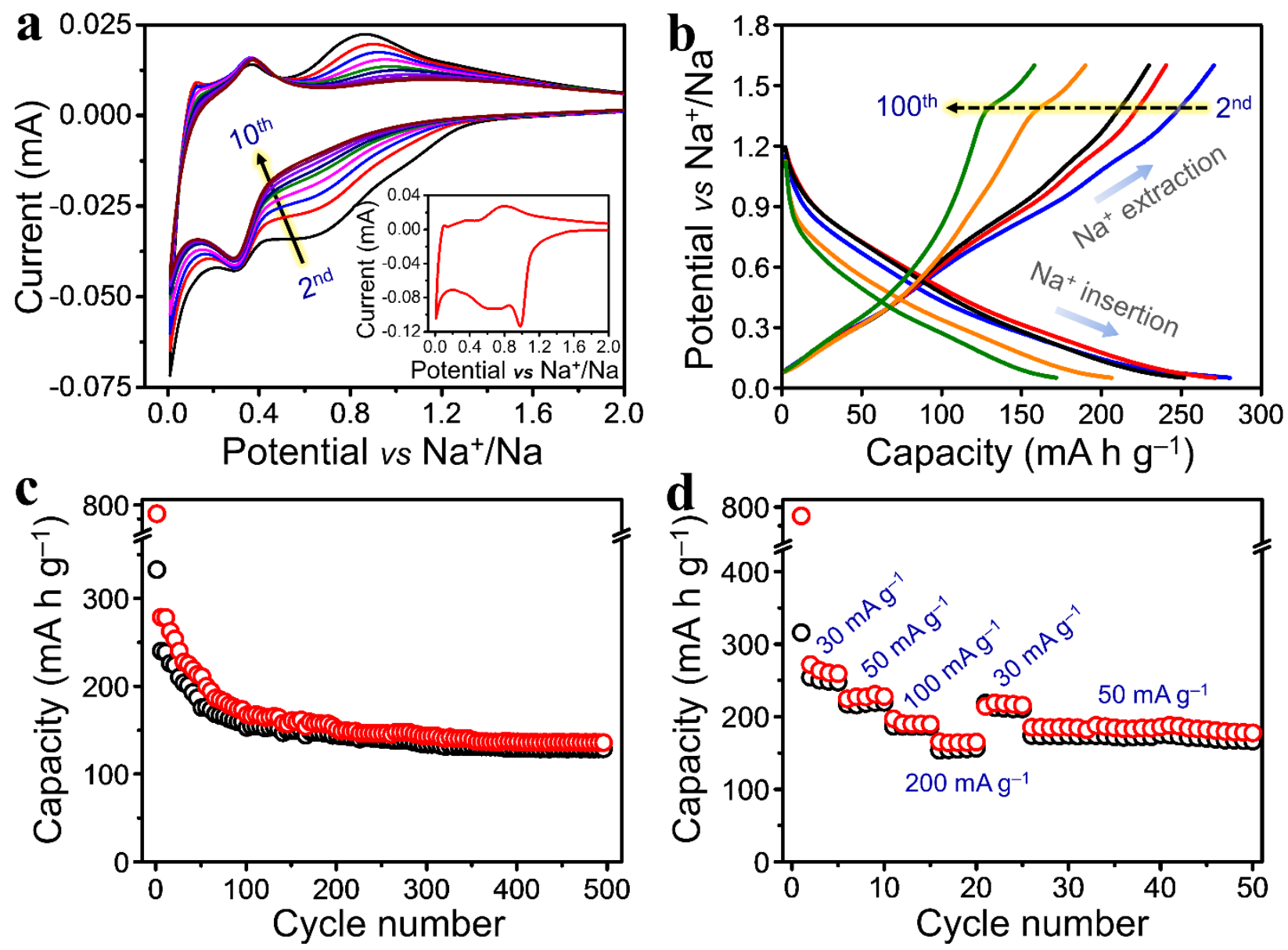

Figure 5: Electrochemical performances of $\mathrm{C} 3 \mathrm{Cy} \mathrm{COF}$ anode in sodium batteries. (a) $\mathrm{CV}$ curves for initial ten cycles at the scan rate of $0.02 \mathrm{mV} \mathrm{s}^{-1}$ (inset: first cycle CV curve). (b) Chrage-discharge profiles for $2^{\text {nd }}, 5^{\text {th }}, 20^{\text {th }}, 50^{\text {th }}$, and $100^{\text {th }}$ cycles at the current rate of $30 \mathrm{~mA}$ $\mathrm{g}^{-1}$. (c) Charge-discharge cycling performance at the current rate of $30 \mathrm{~mA} \mathrm{~g}^{-1}$. (d) Rate performance of $\mathrm{C} 3 \mathrm{Cy} \mathrm{COF}$ anode at different current rates. 


\section{WILEY-VCH}

Figure 6.
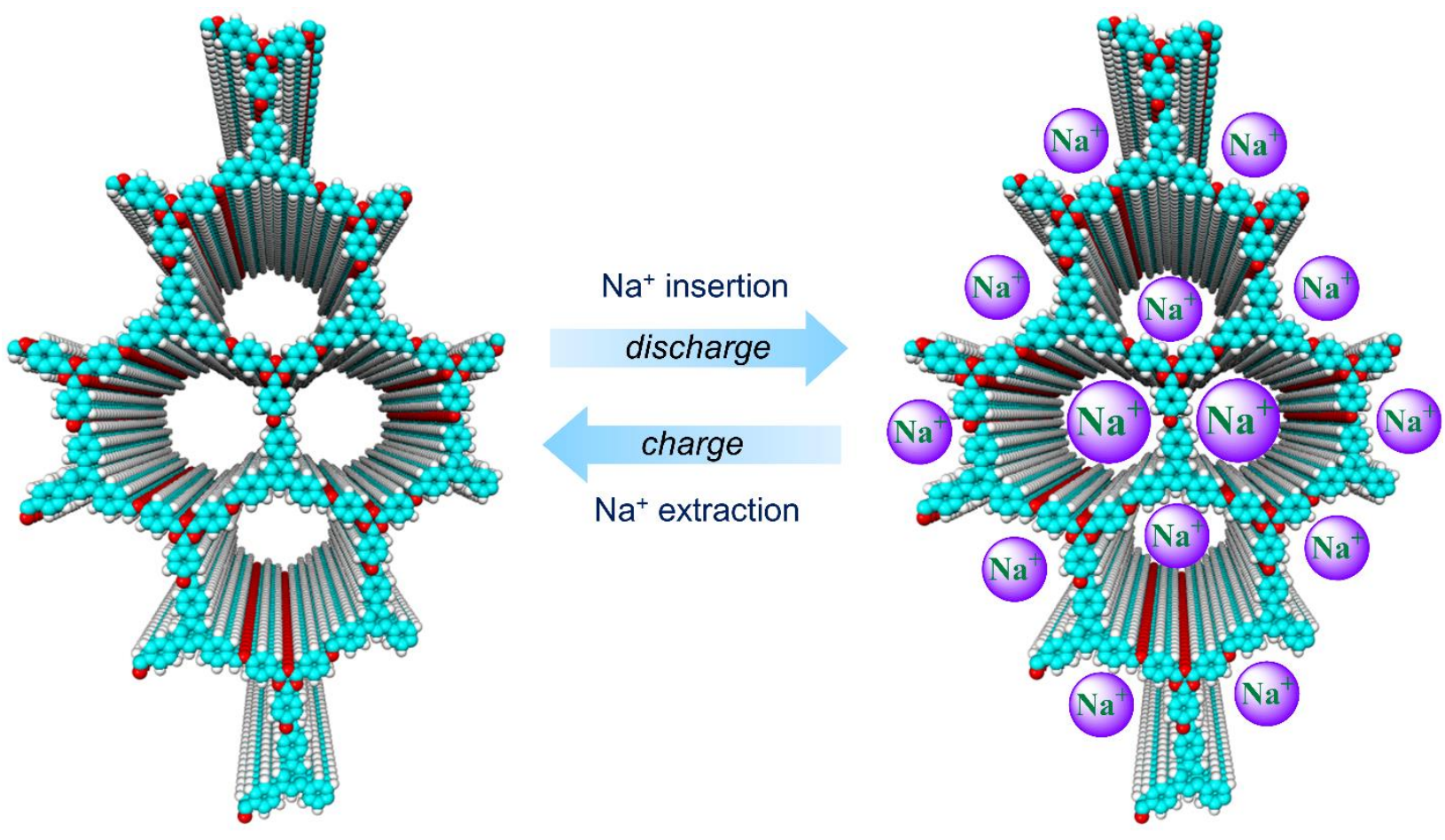

Figure 6: Proposed mechanism of $\mathrm{Na}^{+}$ion storage into $\mathrm{C} 3 \mathrm{Cy} \mathrm{COF}$. 


\section{WILEY-VCH}

Covalent Organic Framework based Microspheres as Anode Material for Rechargeable

\section{Sodium Batteries}

Bidhan C Patra, Sabuj Kanti Das, ${ }^{\dagger}$ Arnab Ghosh, ${ }^{\dagger}$ Anish Raj K, ${ }^{\dagger}$ Parikshit Moitra, Matthew Addicoat, Sagar Mitra, Asim Bhaumik, * Santanu Bhattacharya* and Anirban Pradhan*

B. C. Patra, S. K. Das, Dr. P. Moitra, Prof. A. Bhaumik, * Prof. S. Bhattacharya* and Dr. A. Pradhan*, Indian Association for the Cultivation of Science, Jadavpur, Kolkata 700032, INDIA.

Email-msab@iacs.res.in (Prof. A. Bhaumik), director@iacs.res.in (Prof. S. Bhattacharya) and msap5@iacs.res.in (Dr. A. Pradhan)

A. Ghosh, A. R. K, Prof. S. Mitra, Indian Institute of Technology, Bombay, Powai, Mumbai, Maharashtra 400076, INDIA.

Dr. M. Addicoat, School of Science and Technology, Nottingham Trent University, Clifton Lane, Nottingham, NG11 8NS, UK.

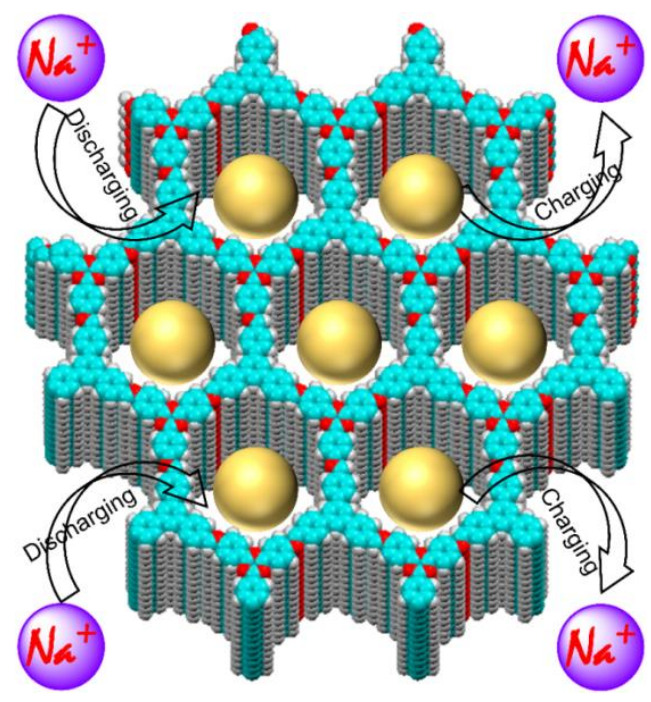

